\title{
Perception, Knowledge and Attitude of Developing Country Pregnant Mothers about Anesthesia for Cesarean Section
}

\author{
Bedru Jemal ${ }^{1}$, Million Tesfaye ${ }^{2}$, Mengistu Alemu ${ }^{2, *}$ \\ ${ }^{1}$ Department of Anesthesia, College of Health Sciences, Dilla University, Ethiopia \\ ${ }^{2}$ Department of Anesthesia, College of Health Sciences Jimma University, Ethiopia
}

Copyright $(\mathcal{C} 2016$ by authors, all rights reserved. Authors agree that this article remains permanently open access under the terms of the Creative Commons Attribution License 4.0 International License

\begin{abstract}
Knowledge about a type of Anesthesia to be used for cesarean section is not well investigated in developing countries. Knowing types and complications of anesthesia for Caesarean section will help mothers to have less stress and decide on their anesthetic choice. This study aimed to assess perception, knowledge and attitude of pregnant mothers towards Anesthesia for Cesarean section. A hospital-based cross-sectional study was conducted to assess knowledge and attitude of pregnant mothers attending antenatal care at Jimma University specialized hospital. Convenience sampling method was used to select participants from May 5 up to June 5, 2014. Chi-square and p-values were also calculated, and P- value $<0.05$ was considered as significant association. $147(69.7 \%)$ women in our survey were found totally unaware about various options of anesthesia technique. Fear of seeing things $(60.3 \%)$ and previous experiences (7.94) were the main reasons for choosing general anesthesia in our population. The women who wanted to see their baby at birth, which accounts $12.6 \%$ and wants to be awakened during operation, which accounted to $6.54 \%$, considered regional anesthesia as a safer technique. Most of the studied population is unaware of the existence of different anesthesia technique. The major source information about anesthesia was from experience, and most of the patient has no knowledge about importance of pre-operative evaluation.
\end{abstract}

Keywords Pregnant Mothers, Anesthesia, Developing Country, Knowledge

\section{Introduction}

The type of anesthesia techniques can be expected to differ between countries and culture, and probably this could be the reason of low demand of regional anesthesia in developing countries $[1,2]$
Despite different factors affecting the choice of anesthesia type many anesthetists give anesthesia without considering the factors which lead to the patient's exposure to multiple drugs. Hospitals are also obligated to expand more money for anesthetic drugs and for treating complication Caesarean section is the commonest type of operative delivery commonly used worldwide in condition where the normal vaginal delivery fails [3].

General Anesthesia and spinal anesthesia are the options that are available for procedures like cesarean section in developing countries. Pregnant women's knowledge and attitude about these techniques are very important for mothers to come to hospital and deliver because they may have fear of complications and even up to death. $[10,11]$

Their decision to undergo caesarean section is also affected by knowing that anesthesia will be administered, and they are not going to feel pain during surgery. [10]

During Ante natal follow up even though some mothers ask about their delivery mechanisms, few know about the option of undergoing caesarean section under anesthesia. Hence, if there is an indication, they can choose general or spinal anesthesia.

All drugs have their own side effect. Anesthetic drugs are one of the most potentially dangerous drugs if they are not used properly. In the appropriate choice of anesthesia is a common problem in Ethiopia, which needs judgments of anesthetist, which should be decided on the same factors that lowers the patient's mortality and mortality. [12,13]

In Ethiopia, even though there are many researches done on surgical procedures, they failed to address type of anesthesia for cesarean delivery. The aim of this research is to fill this gap and show knowledge and attitude pregnant mothers towards the type of anesthesia for professionals so that it will aid in the usage of the right type of anesthesia.

Therefore, this research will show the knowledge and attitude of pregnant mothers towards the type anesthesia for $\mathrm{c} / \mathrm{s}$ to initiate anesthetists to use appropriate anesthetic choice depending on the factors which leads to good anesthetic 
management and less hospital cost for anesthetic drugs.

This study tires to address type of anesthesia needed for cesarean delivery despite different factors and also this study will serve as a base line for further studies.

\section{Methods and Participants}

\subsection{Study Area and Setting}

The study was conducted in Jimma University specialized hospital. Currently it became the only teaching and referral hospital in the southwestern part of the country Currently it is the only teaching and referral hospital in the southwestern part of the country, providing services for approximately 15,000 inpatient, 160,000 outpatient attendants, 11,000 emergency cases and 4500 deliveries in a year coming to the hospital from the catchment population of about 15 million people. The study was conducted from May 5 up to June 5, 2014.

\subsection{Study Design}

Hospital based cross sectional study design was used.

\subsection{Sample Size Determination}

convenience sampling technique we included Pregnant women's who are available during the study period and all pregnant woman's who refuse to be part of the study, unconscious and mental retarded pregnant women's during the study period were excluded.

\subsection{Data Collection}

A structured questionnaire with both open and closed ended questions was used to collect the data. For data collectors training was given on objectives of the study and on the instrument any woman who was interviewed had her antenatal card marked ' $\mathrm{AN}$ ' to avoid repeat recruitment during any subsequent clinic attendance. Data was checked for completeness before entering to SPSS version 16.

\subsection{Data Analysis}

SPSS version 16 was used to analyze the data. Chi-square and $\mathrm{p}$ values were calculated. $\mathrm{P}<0.05$ was taken as significant association.

\subsection{Ethical Approval}

An ethical clearance was issued by the Jimma University School of health science and letter of permission was gained from the medical director of the hospital. The client oral consent was the pre-requisite for the data collector. The potential benefit of the research was explained to the participants. The confidentiality of the participants was kept. The information gained from the participants was kept anonymously.

\subsection{Operational Definitions}

Attitude: ways of thinking of the study subject, about type of anesthesia for cesarean section. It was measured using a Likert scale.

Knowledge: defined in this study, from total knowledge related question, if the pregnant women correctly respond less than $60 \%$ categorized as having poor knowledge.

\section{Results}

A total of 67 women out of 214 (31.3\%) were aware about the existence of different anesthesia techniques. Majority of them were house wives of between 25- 29 years of age $(39.7 \%)$ and experience were found to be a major source of information. Out of 214, 42(17.42\%) women had previous experience of anesthesia for caesarean section, and 10 patients have previous experience from other surgeries and not all of them chose a similar type of anesthesia. From total studied population, 21 women have knowledge of importance of pre-operative assessment, and most of them respond as pre-operative assessment is to decrease risk intra operative complication. (Table1)

$77 \%$ and $23 \%$ of pregnant women preferred general anesthesia and Spinal anesthesia respectively.(Figure 1)

A total of 37(88\%) women received general anesthesia in the past and $5(11.9 \%)$ out of them selected regional anesthesia. Fear of seeing things $(60.3 \%)$ and previous experiences (7.94) were the main reasons for choosing general anesthesia in our population. The women who wanted to see their baby at birth, which accounts $12.6 \%$ and wants to be awakened during operation, which accounted to $6.54 \%$, considered regional anesthesia as a safer technique. (Table 2)

$71.9 \%$ of women fear to undergo Anesthesia due to fear of sudden death, $15.9 \%$ due to fear of pain and $12.2 \%$ due to fear of delayed awakening. (Figure 2)

23, 5 patients have knowledge of general and spinal anesthesia due to previous exposure. Anesthetists are as a source of information accounts of 21 patients and 17 patients. (Table 3)

A complication during previous $\mathrm{C} / \mathrm{S}$ operation, nausea and vomiting accounts $28.57 \%$ with spinal anesthesia while sore throat accounts $10.14 \%$ with general anesthesia. (Table 4)

Univariate analysis carried out to see the factors associated with the women's knowledge regards options of anesthesia type for caesarean section is associated with occupational status (civil servant). (Table 5) 
Table 1. Socio demographic characteristics and distribution

\begin{tabular}{|c|c|c|c|c|c|c|}
\hline Variable & $\mathrm{N}$ & $\mathrm{N}(\%)$ & $\begin{array}{l}\text { Have a knowledge } \\
\text { about type of } \\
\text { anesthesia for } \mathrm{c} / \mathrm{s}\end{array}$ & Percent & p-value & $\mathrm{X}$ \\
\hline \multicolumn{7}{|l|}{ Age years } \\
\hline$<25$ & 64 & 29.9 & 16 & 25 & \multirow{4}{*}{0.949} & \multirow{4}{*}{0.359} \\
\hline $25-29$ & 85 & 39.7 & 25 & 29.4 & & \\
\hline $30-34$ & 43 & 20.1 & 11 & 25.6 & & \\
\hline 35 and above & 22 & 10.3 & 5 & 22.7 & & \\
\hline \multicolumn{7}{|l|}{ Occupation } \\
\hline House wife's & 171 & 79.9 & 35 & 20.46 & \multirow{3}{*}{0.005} & \multirow{3}{*}{10.6} \\
\hline Civil servant & 11 & 5.14 & 9 & 81.8 & & \\
\hline Others & 32 & 14.95 & 13 & 40.6 & & \\
\hline \multicolumn{7}{|l|}{ Parity } \\
\hline Primi gravida & 122 & 57 & 22 & 18 & \multirow{2}{*}{0.013} & \multirow{2}{*}{6.13} \\
\hline Multi gravida & 92 & 43 & 35 & 38 & & \\
\hline \multicolumn{7}{|l|}{ Income } \\
\hline$<1000$ & 28 & 13 & 13 & 46.42 & \multirow{4}{*}{0.002} & \multirow{4}{*}{15.4} \\
\hline $1000-1500$ & 18 & 8.41 & 10 & 55.5 & & \\
\hline$>1500$ & 10 & 4.67 & 6 & 60 & & \\
\hline No income & 158 & 73.83 & 28 & 17.72 & & \\
\hline \multicolumn{7}{|l|}{ Previous operation } \\
\hline Yes & 52 & 24.3 & 29 & 55.76 & \multirow{2}{*}{0} & \multirow{2}{*}{15.2} \\
\hline No & 162 & 75.7 & 28 & 17.2 & & \\
\hline
\end{tabular}

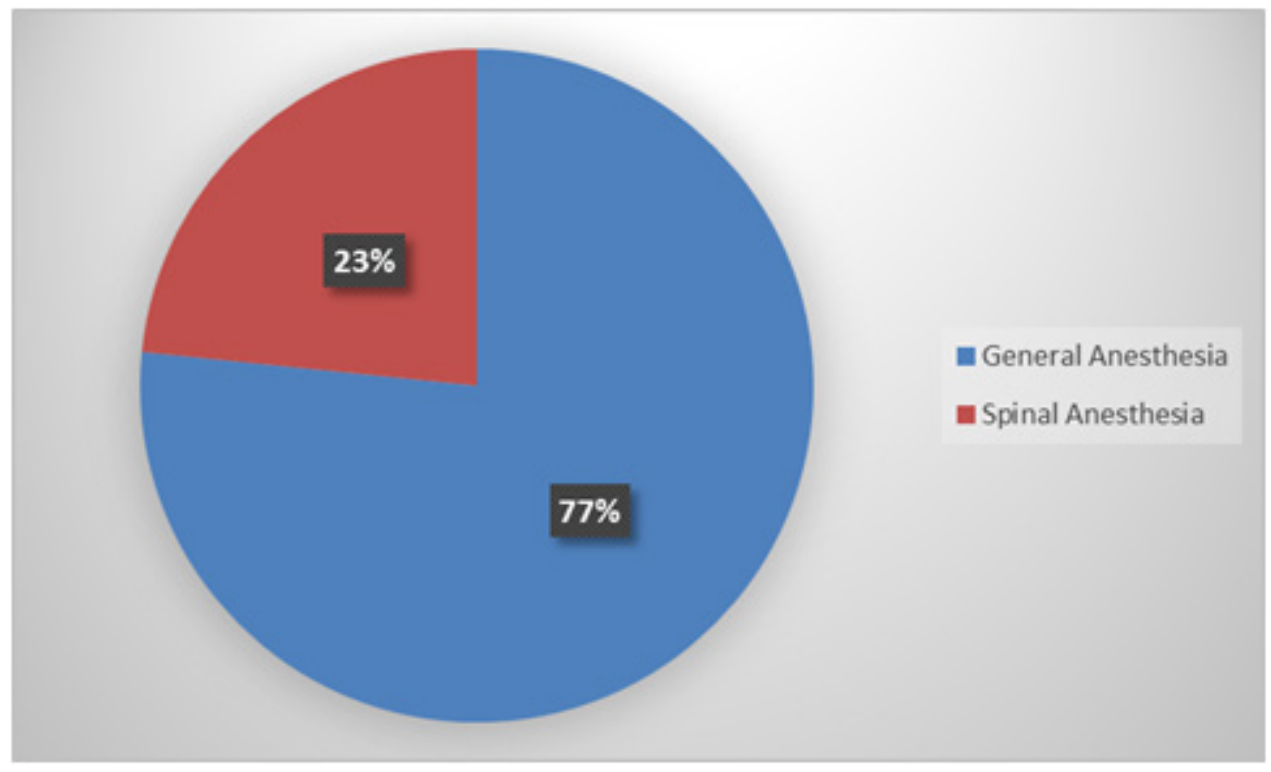

Figure 1. Preference of Anesthesia type by pregnant mothers

Table 2. Reason for preferring of general and regional anesthesia

\begin{tabular}{|c|c|c|}
\hline Variables & N & Percent \\
\hline Reason preferring GA & & 60.3 \\
\hline Fear seeing things during surgery & 129 & 7.94 \\
\hline Previous experience & 17 & 6 \\
\hline Fear of hearing noise during surgery & 13 & 2.33 \\
\hline It has no or less risk & 5 & \\
\hline Reason for choosing RA & & 12.6 \\
\hline Want to see her baby & 27 & 6.54 \\
\hline Want to be awaked during operation & 14 & 1.87 \\
\hline It is safer method for parturient & 4 & 2.33 \\
\hline Advice of relative & 5 & \\
\hline
\end{tabular}




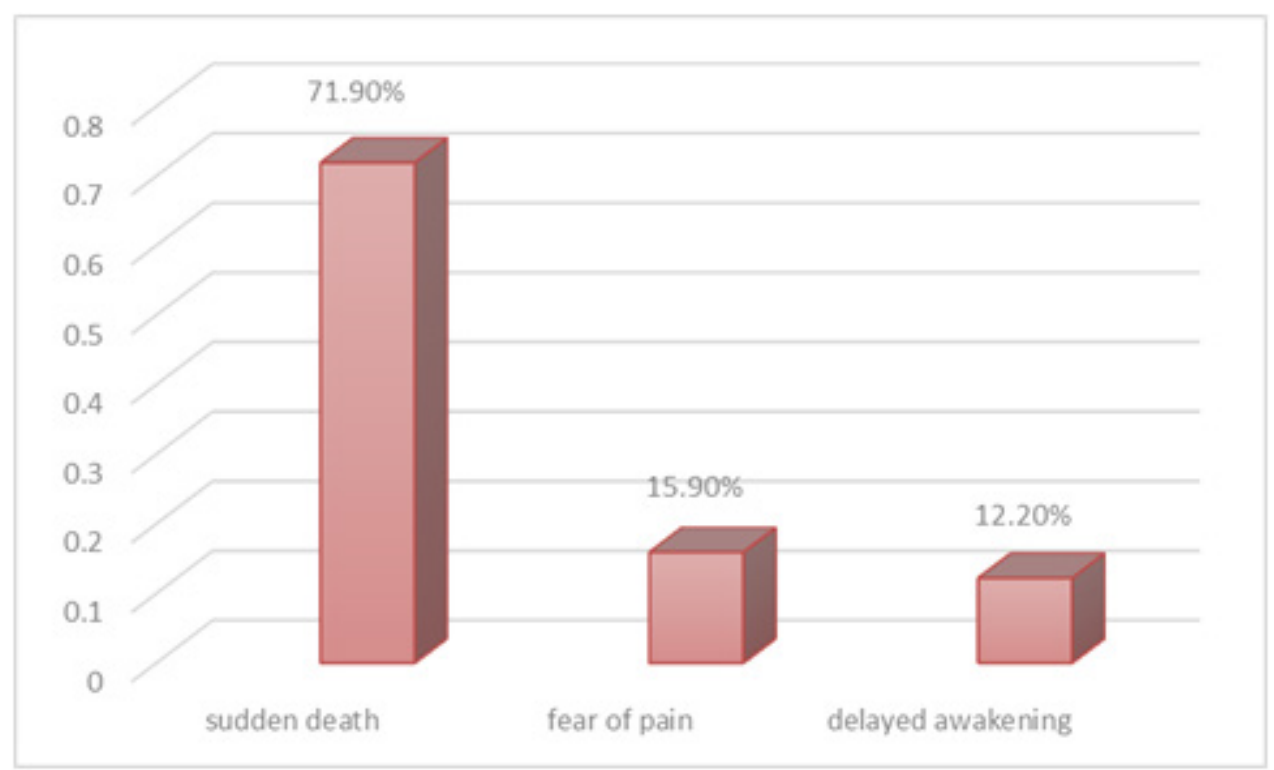

Figure 2. Reason of fear of pregnant mothers to Undergo Anesthesia

Table 3. Knowledge of patient about type of anesthesia and source of information.

\begin{tabular}{|c|c|c|c|c|}
\hline \multirow{2}{*}{$\begin{array}{c}\text { Source of } \\
\text { information }\end{array}$} & \multicolumn{3}{|c|}{ Type of anesthesia } \\
\cline { 2 - 5 } & \multicolumn{2}{|c|}{ General anesthesia } & Regional anesthesia & Both \\
\hline Previous exposure & 23 & 5 & 22 \\
\hline Anesthetist & 21 & 17 & 15 \\
\hline Doctors & 12 & 5 & 16 \\
\hline Nurses & 34 & 16 & 13 \\
\hline
\end{tabular}

*There are multiple responses

Table 4. Complication occurs during previous operation.

\begin{tabular}{|c|c|c|c|c|c|}
\hline \multirow{2}{*}{ Complication } & \multicolumn{2}{|c|}{ GA } & \multicolumn{2}{c|}{ SA } & \multirow{2}{*}{ Percent } \\
\cline { 2 - 6 } & No & $\%$ & No & $\%$ & \\
\hline Sore throat & 7 & 10.14 & - & - & 9.2 \\
\hline Nausea and vomiting & 2 & 2.9 & 2 & 28.57 & 5.26 \\
\hline Respiratory depression & 2 & 2.9 & - & & 2.63 \\
\hline Backache & - & & 3 & 42.85 & 3.95 \\
\hline Others & 2 & 2.9 & 1 & 14.3 & 3.95 \\
\hline
\end{tabular}

Table 5. Awareness about pre-anesthetic assessment

\begin{tabular}{|c|c|c|c|c|c|}
\hline \multirow{2}{*}{ Profession } & \multicolumn{2}{|c|}{ Time of pre-anesthetic assessment } & \multirow{2}{*}{ Percent } & \multirow{2}{*}{ Chi square } & P-value \\
\cline { 2 - 4 } & $\begin{array}{c}\text { On the day of } \\
\text { surgery }\end{array}$ & $\begin{array}{c}\text { One day before } \\
\text { surgery }\end{array}$ & 7.2 & & \\
\hline Civil servant & 2 & 7 & 2.34 & \multirow{2}{*}{2.046} & 0.562 \\
\hline House wife & 3 & 2 & 3.3 & \\
\hline Others & 3 & 4 & 9.98 & \\
\hline Total & 8 & 13 & & \\
\hline
\end{tabular}




\section{Discussion}

Most of the researches showed in last few decades for quality improvement in anesthesia techniques for caesarean section were either focused on drugs to prove their safety or on equipment like spinal and epidural needles to facilitate regional anesthesia. Regional techniques for pregnant women are now considered the technique of choice due to several advantages including decreased risk of gastric aspiration, avoidance of exposure of anesthetic depressant effects of drugs on neonates and lesser incidence of blood loss during surgery $[37,38]$. The obstetric population very often refuses regional anesthesia or analgesia for caesarean or vaginal delivery. This study has focused towards the common factors responsible for the refusals of regional anesthesia e.g. lack of awareness, fear and misconceptions associated with these techniques.

The result found in this study show that majority of pregnant patient attending hospital has no awareness about different anesthesia technique. This result comparable to study found at the Komfo Anokye Teaching Hospital (KATH), Kumasi, Ghana majority of pregnant women attending the hospital were aware of different anesthesia type [39]. The reason why majority women in this study have no awareness can be attributed to a low level of education, rural residence, inadequate resources, and low socioeconomic status as reasons for poor awareness in their studies.

In this study $31.3 \%$ of women were aware about the existence of different anesthesia techniques for caesarean section and the study done at Aga khan university hospital, Karachi Pakistan has shown that $82.4 \%$ of women were aware about the existence of various anesthesia techniques for caesarean section. This is much higher as compared to previous work conducted in developing countries [1, 2]. However it may not reflect a true picture as the tertiary care hospital, where the study was conducted, is a private hospital affiliated with an international university and only upper middle and high economical class patients can afford the medical cost. The reason for low number in this study was due majority of studied population was house wife's and illiterates and survey done in Aga khan university hospital $69 \%$ of women were graduates and sufficient evidence suggests that education enhances awareness on types of anesthesia techniques [3,40].

This study found significant association between knowledge on options of anesthesia technique and occupation, income and parity. The younger age group (25-29years) had good knowledge as compared to 30 years and above and similar findings have been reported in survey done in Pakistan on similar objective. Because the younger age group is computer literate and can acquire information on medical treatment from the internet and other media, this could be the most likely explanation.

This study also showed that females who were housewives had less knowledge regarding options of anesthesia technique as compared to the civil servant women, which is similar to the study done in Pakistan. This survey showed that women with previous experience of anesthesia had good knowledge on anesthesia techniques as compared to those without previous exposure; this is contrary to a study conducted in India in which previous history of anesthesia had no association with increased awareness [11, 41]. Although previous surgery enhanced women's knowledge about anesthesia options, yet not all of them selected the same type of anesthesia as they had in the past. This signifies the importance of previous experience of the patient.

Regarding sources of knowledge about options of anesthesia, experience were the major source contrary to the study conducted in Pakistan the major source of information is anesthetist.

In this study, 90.78\% operated under GA compared to 9.21\% of RA, compared to study in Aga khan university hospital $48.3 \%$ opted general anesthesia as compared to $33.4 \%$ of regional anesthesia and this is well matched with trends in Nigeria. However these findings do not correlate with trends in the developed countries where rate of regional anesthesia is more than $90 \%$ for elective caesarean section and general anesthesia is used in only $9 \%$ of cases. Presently in most parts of Europe and USA the rate of general anesthesia is as low as 3\% which seems unbelievable in our population.

The major reasons of preferring general anesthesia identified in this study were, fear of seeing things during surgery $(60.3 \%)$ and previous experience of general anesthesia $(7.94 \%)$ compared to the study in Pakistan previous experience of general anesthesia is the major reason. This shows poor knowledge and misconnects of our women about safety of general anesthesia for caesarean section. The most common reason for preferring regional anesthesia was the understanding of women $(74.5 \%)$ about it as a safer technique for caesarean section according to the study in Pakistan Aga khan university hospital, but in this study the major reason of preferring RA was want to see their baby. [1]

In summary this survey showed that our women are not well aware about the existence of anesthesia techniques and they do reveal lack of knowledge about their risks and benefit. Further work needs to be done in this regard to increases the knowledge women about the technique of anesthesia.

\section{Conclusions}

Most of the studied population is unaware about the existence of different anesthesia technique. The major source information about anesthesia was from experience and most of the patient has no knowledge about importance of pre-operative evaluation. This may be a factor for decision and accepting possible complications that may arise during anesthesia for cesarean section among pregnant mothers. Institutions should have to aware their patients about possible interventions done and anesthesia techniques to enhance patients' confidence and knowledge to choose appropriate anesthesia type. Finally by creating awareness 
we can decrease perception and attitude of patients about fear to undergo anesthesia.

\section{Acknowledgements}

We are thankful to Jimma university specialized hospital staffs for helping us during data collection.

\section{REFERENCES}

[1] Gurunathan U, Jacob R.A questionnaire survey on Patients' attitudes towards epidural analgesia in labour. Hong Kong Med J 2007; 13: 208-15.

[2] Okafor UV, Ezegwui HU, Ekwazi K. Trends of different forms of anaeshesia for Caesarean section in South-eastern Nigeria. J Obstet Gynaecol 2009; 29: 392-5.

[3] Minhas MR, Kamal R, Afshan G, Raheel H. Knowledge, attitude and practice Of Parturient regarding epidural analgesia for labor in a university hospital in Karachi. J Pak Med Assoc. 2005; 55: 63-6.

[4] Alan H Decherhecy, Lauren Nathan; current obestric and gyne diagnosis treatment; 9th Ed; p (518-527), 2003.

[5] Old man M, McCartney A, rawsonr, perals a godson and godson $\mathrm{j}$ chain; surgeon's attitude towards regional anaesthesia; anaesthesia Analg 2004 may; 98(5):1486-90.

[6] Mattew old man, Collin, Andrea; attitude and knowledge regarding regional anaesthesia; CJA; 2005 Nov; 52(9):899-903.

[7] Wirakusmah, FF, Maternal and prenatal morbidity and mortality associated with CS in Indonesia; Jobs/Gyn.1995 Oct; 2(5):475-81.

[8] Cisse CT, andramaduy G, Faye $\mathrm{O}$ and diouf A; indication and prognosis of CS at Dakar university hospital; J gynobs; 1995; 24(2):194-7.

[9] Dauak-c; lasrik-E: the cause of pregnancy and fetal outcomes after CS; 97(23) Dec 1985; 880-3

[10] Keith G .Allman oxford handbook of anesthesia. 2nd edition. UK legoprint: 1990

[11] Shevde K, pangopoulos G. A survey of 800 patients' knowledge, attitude, and concerns regarding anesthesia. Anaesth Analg 1991; 73:190-8.

[12] Robins K, Lyons G. Ans-Analg international society 1990; 70: 29-35.

[13] NganKee WD, Hung VY, Roach VJ, LauTK. A survey of factors influencing patients' choice of anesthesia for caesarean section. Aus N Z J Obestet Gynecol 1997; 37:300-3.

[14] Fisccher B. Chauddhari M. Technique of epidural block. Anesth intensive care Med 2006; 7: 422-426

[15] DIC W. General Veersus spinal anesthesia for elective and emergency Surgery University of hospital of maiz Germany pub med. Jan. 1992; 1-2

[16] Bay M.Kehlet H. prospective national wide assessment of herniorrphy is Denmark, lance 4, 2001; 358: 1128.

[17] AfolabiBB, LesiFE SO Cochrane Database systRev.2012; 10:CD004350.

[18] Hawkins JL, Koonin LM, Palmer SK, et al: Anesthesia related deaths during obstetric delivery in the USA, 1979-1990. Anesthesiology 86: 227-284, 1999.

[19] Department of Anesthesiology and Pain Management, Parkland Memorial Hospital, Dallas, Texas 75235-9068, USA

[20] Depp, R; Cesarean delivery and other surgical procedures in Gabbe SG, Niebly JR, Simpson JL (eds): obstetrics normal and problem pregnancies, New York Churchil Livingstone, 1991, P635.

[21] Bauer ME, Kountanis JA, Tsen LC, Greenfield ML, Mhyre JM. SO Int J obestet Anesth.2012 oct.21 (4):294-309.

[22] Hawkins JL, Gibbs GP, arbeanm, et al: obstetrics anesthesia work force survey, 1981 Vs 1992, Anesthesiology 87: 135 $-143,1997$

[23] Dyer RA, Piercy JL, Reed AR, Lombard CJ, Schoemen LK, James MF SO Anesthesiology.2008; 108(5):805.

[24] Kwawukume EY. In: caesarean section in comprehensive obstetrics in the tropics. First edition. Kwawukume EY, Emuveyam EE, and editors. Dansoman, Accra: Asante and hittscher printing press limited: 2002.Jan, PP 321-329.

[25] Annual report, reproductive and child health unit: public health division, Ghana health service.2003, PP.

[26] Olapado OT, sotunsa JO; sule-Odu AO. arise in caesarean birth rate in Sagmu, Nigeria: a reflection of changes in obestric practice's obstet gynecol.2004 Jun; 24(4):377-381.

[27] Awoyinka BS, Ayinde OA, and Omigobodun AO. acceptability of caesarean delivery to antenatal patients in a tertiary health facility in south-west Nigeria obstet Gynecol.2006 Apr; 26(3):208-210.

[28] McDonnell NJ peach MJ, Clavis OM, Scott KL, ANZCA trial group SO Int J obstet Anesth.2008; 17(4):294.

[29] Shell; KU, Russel IF. A survey of anaesthetic technique used for CS in the UK in 1997.Int J obstet Anesth 200; 9:160-7.

[30] Frederickson MC, Glassen berg R, Stina C. placenta previa: a 22 year analysis. Am J Obstet gynecol 1999; 180:1432-7.

[31] Wanyonyis D, sequel E.pubura T; retrospective study on CS rates in Nairobi; East Africa medical J; 2006 Dec; 83(12):651-8.

[32] Mc Capon RA, calting S .time required for surgical readiness in emergency CS: spinal compared with GA, Int $\mathbf{J}$ obstet Anesth 2003; 12:178-82.

[33] Kennedy BW, ThropJM, FitchW, MillarK. the theatre environment and a wake patient Obstet gynecol 1992; 12:407-11.

[34] Lewis G, Drife J editors. Why mothers die 1997-1999. The $5^{\text {th }}$ report of the confidential enquires in to maternal deaths in UK. london: RCOG press; 2001. 
[35] Yau G, Gin T, Ewart MC, Koutur CF, leang RK, Oh TE SO Anesthesia.1991;46(1):20

[36] Waterston M, Beweley S, Wolfe C. incidence and predictors of severe obestric morbidity: case control study. BMJ 2001; $322 ; 1089-93$.

[37] Roizen MF: Preoperative laboratory testing: necessary or overkill? Canadian Journal of Anesthesia 2004, 51(90001):13. Can Anes Soc

[38] Schein OD, Katz J, Bass EB, Tielsch JM, Lubomski LH, Feldman MA, Petty BG, Steinberg EP: The value of routine preoperative medical testing before cataract surgery.

[39] Chung F, Yuan H, Yin L, Vairavanathan S, Wong DT: Elimination of preoperative testing in ambulatory surgery.

[40] Jathar D, Shind VS, Patel RD, Naik LD. A study of patient's perception about knowledge of anaesthesia \& anesthesiologist. Indian J Anaesth 2002; 46: 26-30.

[41] Mittal MK. Sethi AK, Tyagi A, Mohta. Awareness about anesthesiologist and scope of anesthesiology in non-surgical patients and their attendants. Indian J. Anaesth 2005; 49: 4928. 